\title{
Different Compatibility Approaches to Improve the Thermal and Mechanical Properties of EVA/Starch Composites
}

\author{
Hassiba Hamadache $\left(\mathbb{D},{ }^{1}\right.$ Hocine Djidjelli, ${ }^{1}$ Amar Boukerrou, ${ }^{1}$ Mustapha Kaci, ${ }^{1}$ Jofre-Reche José Antonio, ${ }^{2}$ \\ José Miguel Martín-Martínez ${ }^{2}$ \\ ${ }^{1}$ Laboratoire des Matériaux Polymères Avancés (LMPA), Département Génie des Procédés, Université de \\ Abderrahmane Mira, Béjaia, 06000, Algeria \\ ${ }^{2}$ Adhesion and Adhesives Laboratory, University of Alicante, 03080 Alicante, Spain
}

\begin{abstract}
Biocompostable composites based of ethylene-co-vinyl acetate (EVA) copolymer were prepared by using a twinscrew extruder. The compatibility between EVA/starch composites were improved either by addition of polyethylene-grafted maleic anhydride (PE-g-MA), or by reactive extrusion with maleic anhydride (MA) and benzoyl peroxide. The crystallinity of the non-compatibilized composites increased with the starch content. The addition of PE-g-MA increased the crystallinity of the composites made with up to $20 \mathrm{wt} \%$ of starch. The thermal stability of EVA/starch composites decreased with increasing the starch content, and the addition of PE-gMA compatibilizer enhanced the thermal stability of the composite. The in-situ grafting with MA and PBO led to an increase in the thermal stability of the composites containing higher amounts of starch. Further, the mechanical properties of the compatibilized EVA/starch composites were improved with increasing the starch content and this was ascribed to the improved interfacial interactions between starch and EVA. POLYM. COMPOS., 2018. @ 2018 Society of Plastics Engineers
\end{abstract}

\section{INTRODUCTION}

In recent years, the addition of starch to synthetic polymers has become of growing interest for the plastics industry due to its biodegradability and biocompostability [1]. The addition of biodegradable starch in polymers contributes to an increase in the use of renewable resources. Furthermore, the biocompatibility of starch has an interest in medical applications [2-5]. On the other hand, it has been reported that the addition of starch to polyethylene accelerates its degradation upon exposure to biotic environmental condition [6]. As a result, the mechanical properties are

Correspondence to: H. Hamadache; e-mail: hamadachehassiba@yahoo.fr DOI $10.1002 /$ pc. 25179

Published online in Wiley Online Library (wileyonlinelibrary.com).

(C) 2018 Society of Plastics Engineers reduced inducing the deterioration of the material and subsequently its biodegradation, which is also enhanced by the incompatibility and poor interfacial adhesion between the hydrophilic starch and the hydrophobic polymer leading to poor mechanical properties.

As a matter of facts, several studies have been carried out for improving the compatibility of starch-polymer blends including the starch modification [7-12], the addition of plasticizer $[13,14]$, the polymer modification $[15,16]$, and the compatibilization with coupling agents $[17,18]$. The compatibilization of polymer blends containing starch can be performed either by reactive extrusion [19-23] or by addition of a coupling agent [24-27]. Pedroso and Rosa. [25] have shown that polyethylene-grafted maleic anhydride (PE- $g$-GMA) compatibilizer increased the tensile strength of low-density polyethylene (LDPE)-starch blend resulting from improved interfacial interactions. Further, Kahar et al. [26] have also reported that PE-g-GMA compatibilizer significantly increased the tensile strength of high-density polyethylene (HDPE)-natural rubber (NR)/ Thermolplastic Starch (TPS) blends and this have been ascribed to improved interactions at the interphase between TPS and HDPE/NR. Rohani et al. [27] have demonstrated that the mechanical properties of LDPE/(TPS)-kenaf fiber composites were improved in the presence of PE- $g$-MA. Moreover, a reduction in water uptake of the composites was also observed.

For in-situ grafting compatibilization of polymers by reactive extrusion, maleic anhydride (MA) [19-23] and methylene diphenyldiisocyanate (MDI) [28] have been proposed. The grafting reaction is initiated by peroxides such as benzoyl peroxide (BPO) [23] or dicumyl peroxide (DCP) [29]. The literature [30,31] has reported the addition of polylactic acid (PLA)- $g$-starch to improve the compatibility between PLA and starch the results indicated a slight improvement in both tensile strength and elongation at break of the composites. Shujun et al. [32] have reported 
that the thermal stability of TPS/LLDPE blends containing MA in the presence of DCP was improved as compared with the virgin blends.

Depending on the vinyl acetate (VA), ethylene-co-vinyl acetate (EVA) copolymer is a semi-crystalline or amorphous thermoplastic material [33]. EVA shows a good adhesion [34], a good flexibility [35], and controlled mechanical properties [36]. EVA finds a wide range of applications involving the cable industry, membrane preparation, packaging, and so on [37]. EVA is not a biodegradable polymer but its blending with starch may provide certain biodegradability to the blend [23]. Indeed, Piming reported that the addition of $0.9-1.8 \mathrm{wt} \%$ of MA in presence of BPO for in-situ grafting of EVA and starch, caused 6-fold increase in the tensile strength of EVA/starch composites. In addition, by using the Molau test in EVA50/ starch blend containing different amounts of MA, Piming showed that EVA-g-starch copolymer was the major reaction product at a low MA concentration $(\leq 0.9 \mathrm{wt} \%)$. In spite of the great potential of such blend materials in engineering applications, there are however a few studies dealing with the blending of EVA and starch. To the best of our knowledge, there are no studies published on the use of PE- $g$-MA as compatibilizer for EVA/starch blends.

Therefore, the aim of this study was to evaluate the effectiveness of two different compatibilization approaches that is, the addition of PE- $g$-MA as the coupling agent and the reactive extrusion (in-situ grafting) of EVA/starch blends. So far, no comparative study between the two approaches is reported yet in the open literature.

\section{EXPERIMENTAL}

\section{Materials}

EVA copolymer was supplied in pellets by SAEL Oued Smar(Algiers, Algeria) and it contain 18 wt $\%$ of VA. The polymer has a melt flow index of $2.2 \mathrm{~g} / 10 \mathrm{~min}$ (according to TS-AE-E15-3500 test method), and a density of $0.989 \mathrm{~g}$. $\mathrm{cm}^{-3}$. Corn starch was supplied in grain form by Agro Cereal (Moulin, Royal Akbou-Bejaia, Algeria). The average size of the starch particles is $200 \mu \mathrm{m}$.

The chemical products used for compatibilization of EVA/starch blends were MA (98 wt\% purity) supplied by Panreac (Barcelona, Spain), PBO supplied by Aldrich(USA), and PE-g-MA of molecular weight 31,200-112,500 g/mol, supplied by Aldrich(France).

\section{Preparation of EVA/Starch Composites}

$\mathrm{EVA} /$ starch composites were prepared in a twin-screw extruder Micro compounder DSM Xplore (Xplore Instruments BV, Sittard, The Netherlands). The screw characteristics are a length of $150 \mathrm{~mm}$ and a length/diameter ratio of 18. The extrusion temperature was adjusted to $130^{\circ} \mathrm{C} .12 \mathrm{~g}$ EVA and starch were added simultaneously into the
TABLE 1. Compositions of EVA/starch composites.

\begin{tabular}{lccccc}
\hline Composite & $\begin{array}{l}\text { EVA } \\
(\text { wt\% })\end{array}$ & $\begin{array}{l}\text { Starch } \\
(\text { wt } \%)\end{array}$ & $\begin{array}{l}\text { MA } \\
(\text { wt\% })\end{array}$ & $\begin{array}{l}\text { BPO } \\
(\text { wt\% })\end{array}$ & $\begin{array}{l}\text { PE-g-MA } \\
(\text { wt\% })\end{array}$ \\
\hline EVA & 100 & 0 & 0 & 0 & 0 \\
F1 & 90 & 10 & 0 & 0 & 0 \\
F2 & 80 & 20 & 0 & 0 & 0 \\
F3 & 70 & 30 & 0 & 0 & 0 \\
P1 & 85 & 10 & 0 & 0 & 5 \\
P2 & 75 & 20 & 0 & 0 & 5 \\
P3 & 65 & 30 & 0 & 0 & 5 \\
L1 & 89 & 10 & 0.09 & 0.009 & 0 \\
L2 & 79 & 20 & 0.09 & 0.009 & 0 \\
L3 & 69 & 30 & 0.09 & 0.009 & 0 \\
\hline
\end{tabular}

extruder according to the compositions reported in Table 1. The residence time was $10 \mathrm{~min}$ and the rotational speed was $50 \mathrm{rpm}$. After the extrusion step, the molten mixture was injected in mini injection molding machine (Xplore Instruments BV, Sittard, The Netherlands) at $130^{\circ} \mathrm{C}$ and 8 bars for $3 \mathrm{~min}$, to obtain dog-bone specimens (Fig. 1).

The composition codes of the blends in Table 1 consist of a capital letter followed by a number; F corresponds to EVA/starch composite without compatibilizer; P corresponds to EVA/starch composite with PE-g-MA; and the capital latter $\mathrm{L}$ corresponds to EVA/starch composite with $\mathrm{MA}+\mathrm{PBO} ; 1,2$, and 3 indicate 10, 20, and $30 \mathrm{wt} \%$ of starch, respectively. For example, P1 corresponds to the composite containing $10 \mathrm{wt} \%$ of starch and compatibilized with PE-g-MA.

\section{Characterization Techniques}

Differential Scanning Calorimetry. The thermal properties of EVA and EVA/starch composites were analyzed by differential scanning calorimetry in DSC Q100 (TA Instruments, New Castle, DE) under nitrogen (flow: $50 \mathrm{~mL} / \mathrm{min}$ ). A $10 \mathrm{mg}$ of sample was placed in hermetically closed pans. Experiments were carried out in the temperature range from -70 to $+200^{\circ} \mathrm{C}$ at a heating rate of $10^{\circ} \mathrm{C} / \mathrm{min}$. The crystallinity and melting enthalpies were calculated from the second DSC scan.

The degree of crystallinity $(\chi c)$ of the composites was determined according to $E q .1$ :

$$
X_{\mathrm{c}}(\%)=\left(\Delta H_{\mathrm{m}} / \Delta H_{\mathrm{m}}^{0}\right) \times\left(100 / w_{\mathrm{EVA}}\right)
$$

where, $\Delta H_{\mathrm{m}}$ is the melting enthalpy of the composite, $\Delta H_{\mathrm{m}}^{0}$ is the melting enthalpy of $100 \%$ crystalline polyethylene $(288 \mathrm{~J} / \mathrm{g})$ [38], and $w_{\mathrm{EVA}}$ is the amount of EVA in the composite.

Thermogravimetric Analysis. Thermal stability of neat EVA, neat starch and EVA/starch composites were analyzed by thermogravimetry in thermogravimetric analysis (TGA) Q500 (TA Instruments, New Castle, DE). The experiments were carried out by using 5-10 mg sample 


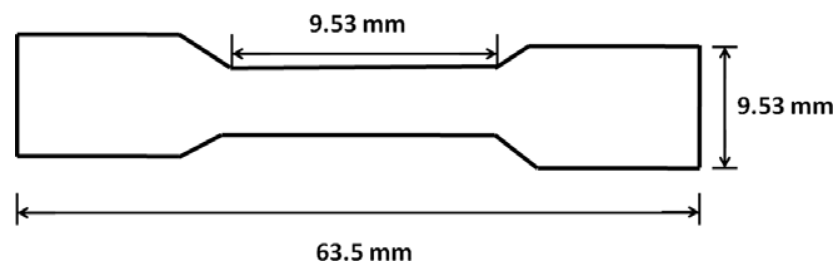

FIG. 1. Shape and dimensions of the composite specimens for stressstrain tests.

in the temperature range $30-850^{\circ} \mathrm{C}$ under nitrogen atmosphere (flow: $50 \mathrm{~mL} / \mathrm{min}$ )at a heating rate of $10^{\circ} \mathrm{C} / \mathrm{min}$. The char material formed during TGA experiment was removed at $850^{\circ} \mathrm{C}$ after keeping the residue during $10 \mathrm{~min}$ under an oxygen flow $(50 \mathrm{~mL} / \mathrm{min})$.

Stress-Strain Tests. The mechanical properties of EVA/starch composites were determined by stress-strain tests using an Instron 4,411 universal testing machine (Instron Ltd., Norwood) at a pulling rate of $10 \mathrm{~mm} / \mathrm{min}$. The tensile values were determined by testing at least five dog-bone shaped specimens for each composite composition (Fig. 1) and the results obtained were averaged.

Scanning Electron Microscopy. Scanning electron microscopy (SEM) was used to observe the topography of EVA/starch composites and also to determine the dispersion state of the starch in the EVA matrix. SEM Hitachi S3000 N (Tokyo, Japan) equipped with Bruker XFlash 3,001 probe for microanalysis (EDS) was used at a voltage of $25 \mathrm{keV}$. Before analysis, the samples were gold coated in SCD-004 metallization unit (Oerlikon Balzers, Liechtenstein) to obtain adequate contrast.

\section{RESULTS AND DISCUSSION}

\section{Characterization of EVA/Starch Composites Containing Different Amounts of Starch}

In this section, the properties of EVA/starch composites with starch content of $10-30 \mathrm{wt} \%$ (referred to F1-F3 in Table 1) were characterized.

TABLE 2. Some parameters obtained from DSC thermogramsof EVA, starch and EVA/starch composites.

\begin{tabular}{lcccccc} 
Composite & Starch $(\mathrm{wt} \%)$ & $T_{\mathrm{c}}\left({ }^{\circ} \mathrm{C}\right)$ & $T_{\mathrm{m}}\left({ }^{\circ} \mathrm{C}\right)$ & $\Delta H_{\mathrm{m}}(\mathrm{J} / \mathrm{g})$ & $\Delta H_{\mathrm{c}}(\mathrm{J} / \mathrm{g})$ & $X_{\mathrm{c}}(\%)$ \\
\hline EVA & 0 & 56 & 86 & 64 & 38 & 22 \\
F1 & 10 & 57 & 85 & 45 & 24 & 18 \\
F2 & 20 & 54 & 86 & 43 & 22 & 19 \\
F3 & 30 & 56 & 85 & 39 & 24 & 20 \\
P1 & 10 & 55 & 85 & 42 & 19 & 18 \\
P2 & 20 & 59 & 84 & 43 & 20 & 20 \\
P3 & 30 & 57 & 84 & 31 & 12 & 16 \\
L1 & 10 & 55 & 86 & 43 & 18 & 18 \\
L2 & 20 & 54 & 86 & 42 & 21 & 19 \\
L3 & 30 & 53 & 86 & 35 & 23 & 17 \\
\hline
\end{tabular}

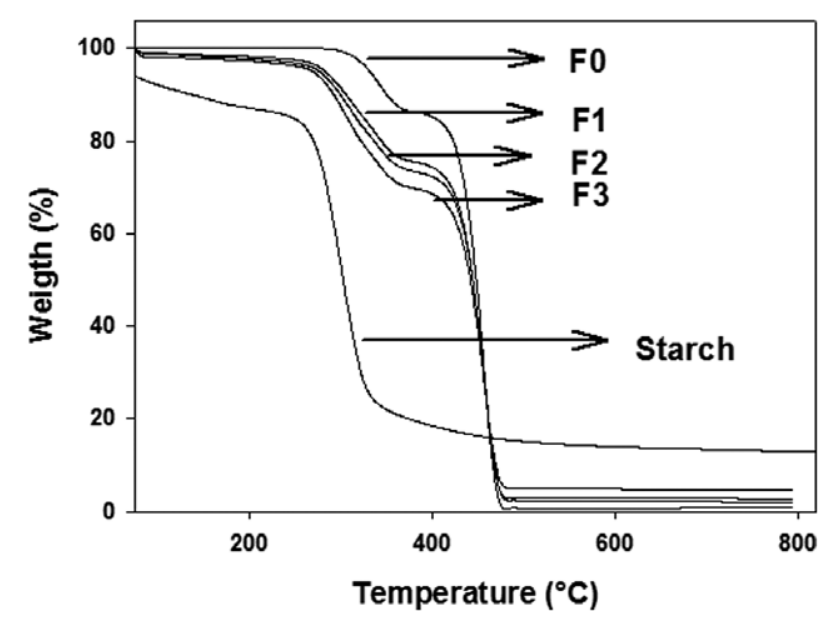

FIG. 2. Variation of the weight as a function of temperature for EVA/ starch composites. TGA experiments.

The influence of starch on the crystallinity of EVA and EVA/starch compatibility was investigated by DSC. Table 2 shows the values of crystallization temperature $\left(T_{\mathrm{c}}\right)$ and melting temperature $\left(T_{\mathrm{m}}\right)$ of ethylene domains in EVA, the crystallization enthalpy $\left(\Delta H_{\mathrm{c}}\right)$ and melting enthalpy $\left(\Delta H_{\mathrm{m}}\right)$ and the crystallinity degree $\left(X_{\mathrm{c}}\right)$ of EVA and non compatibilized EVA/starch composites. Addition of starch does not affect the $T_{\mathrm{m}}$ value of ethylene domains of EVA $\left(84-86^{\circ} \mathrm{C}\right)$, but a decrease in melting enthalpy (from $64 \mathrm{~J} / \mathrm{kg}$ for pure EVA to $39-45 \mathrm{~J} / \mathrm{kg}$ for EVA/starch composites) is observed. Further, the increasing the starch content does not affect significantly the melting enthalpy. Similar trend is also observed for the crystallization enthalpy decreasing from $38 \mathrm{~J} / \mathrm{kg}$ for neat EVA to $22-24 \mathrm{~J} / \mathrm{kg}$ for EVA/ starch blends irrespective of the amount of starch, suggesting lower crystallinity in EVA/starch composites than in EVA. This is consistent with $X_{\mathrm{c}}$ data indicating a slight decrease in the value of EVA/starch composites $\left(X_{\mathrm{c}} \sim 18-20 \%\right)$ compared with that of neat EVA $\left(X_{\mathrm{c}} \sim\right.$ $22 \%$ ) in agreement with the results published by Kim et al. [39]. However, some discrepancies have been also reported in the literature on the effect of starch on polyolefin crystallinity. Indeed, Anderson et al. [40] demonstrated that the crystallinity of LDPE increases by adding starch, thus acting as a nucleating agent for the crystallization of polyethylene. On the other hand, Jagadish and Raj [41] and Sabetzadeh et al. [42] have shown that the crystallinity of polyethylene decreases with increasing the amount of starch. This is, however, contradictory to the work published by Fang-Chyou et al. [43] indicating no effect of starch on polyolefin crystallinity.

TGA thermograms of pure EVA, pure starch and EVA/starch composites without compatibizer are shown in Fig. 2. In TGA thermogram of neat EVA, two weight losses are observed; the first one occurs in the temperature range $250-350^{\circ} \mathrm{C}$, attributed to the removal of acetoxy groups from VA resulting in the elimination of an acetic acid molecule. The second one is located between 400 and $470^{\circ} \mathrm{C}$ and corresponds to the thermal decomposition of polyethylene and vinyl structure produced in the first 

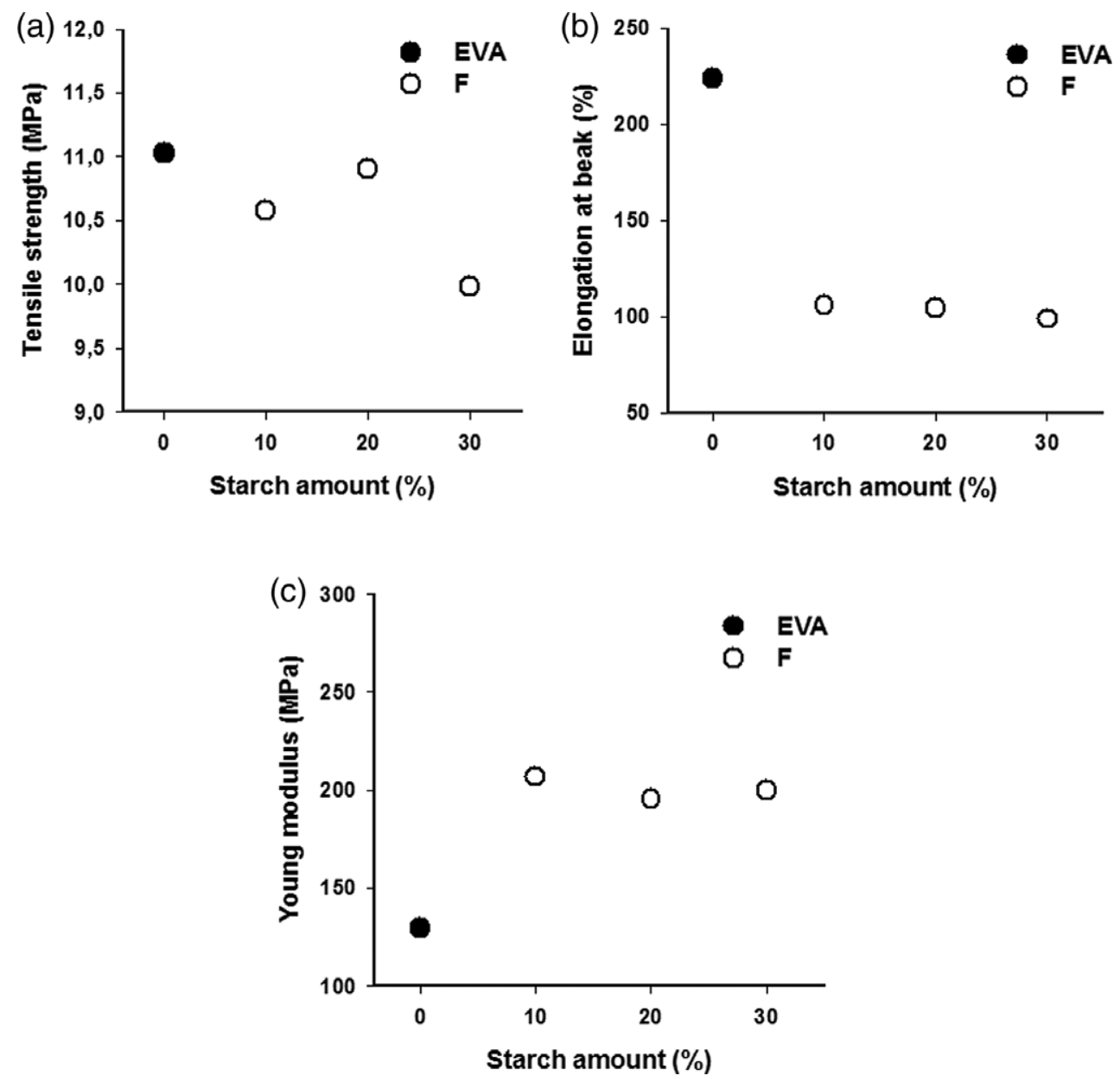

FIG. 3. Variation of the tensile strength (a), elongation at break (b), and Young's modulus (c) of pure EVA and EVA/starch composites.

decomposition step [44]. For neat starch, the TGA thermogram in Fig. 2 shows three thermal decomposition steps. The first decomposition step starts at about $100^{\circ} \mathrm{C}$ and it is attributed to water removal. The second decomposition occurs at $250-320^{\circ} \mathrm{C}$ corresponding to the thermal decomposition of both amylose and amylopectin [45], while the third one recorded at $350-450^{\circ} \mathrm{C}$ corresponds to char formation. TGA thermograms of $\mathrm{EVA} / \mathrm{starch}$ composites (Fig. 2) also show three thermal decomposition steps; the first one at around $100^{\circ} \mathrm{C}$, which is quite small, corresponds to water removal of the starch from the composites. The second starts at lower temperature than the thermal decomposition of EVA indicating that the addition of starch decreases the thermal stability of EVA. According to Dikobe and Luyt [46], the lower thermal stability of polymers containing starch is due to early degradation of the starch particles with respect to that of polymer. In fact, the temperature at which the second thermal decomposition starts is similar in all EVA/starch composites, irrespective of their starch content, and this temperature corresponds to the one of pure starch.

Figure 3 shows the variation of several mechanical properties of EVA/starch composites as a function of their starch content. Figure $3 \mathrm{a}$ and $\mathrm{b}$ shows that the addition of starch decreases the tensile strength and elongation-at-break of EVA/starch composites, respectively, these are more pronounced at higher starch content. Furthermore, the addition of $10 \mathrm{wt} \%$ starch increases Young's modulus of EVA. Similar trend is also observed for the whole composite materials, irrespective of their starch content. Therefore, the addition of starch imparts stiffer behavior to EVA, in agreement with the literature $[47,48]$. In fact, a good interfacial adhesion between the polymeric matrix and the filler is important for controlling the mechanical properties of the composites as the stress transfer is determined by the interfacial properties. The decrease in tensile strength and elongation at break of EVA/starch composites suggests that the introduction of starch particles in EVA matrix produces an important weakness in the bulk due to poor interactions between the EVA matrix and the starch particles. This is also enhanced by the poor compatibility between EVA and starch [27]. It has been reported [49,50] that the incompatible composites show a weak interfacial adhesion, which provides a site for failure initiation.

The adhesion between EVA and starch grains was investigated by SEM. Figure 4 shows the SEM micrographs of the 

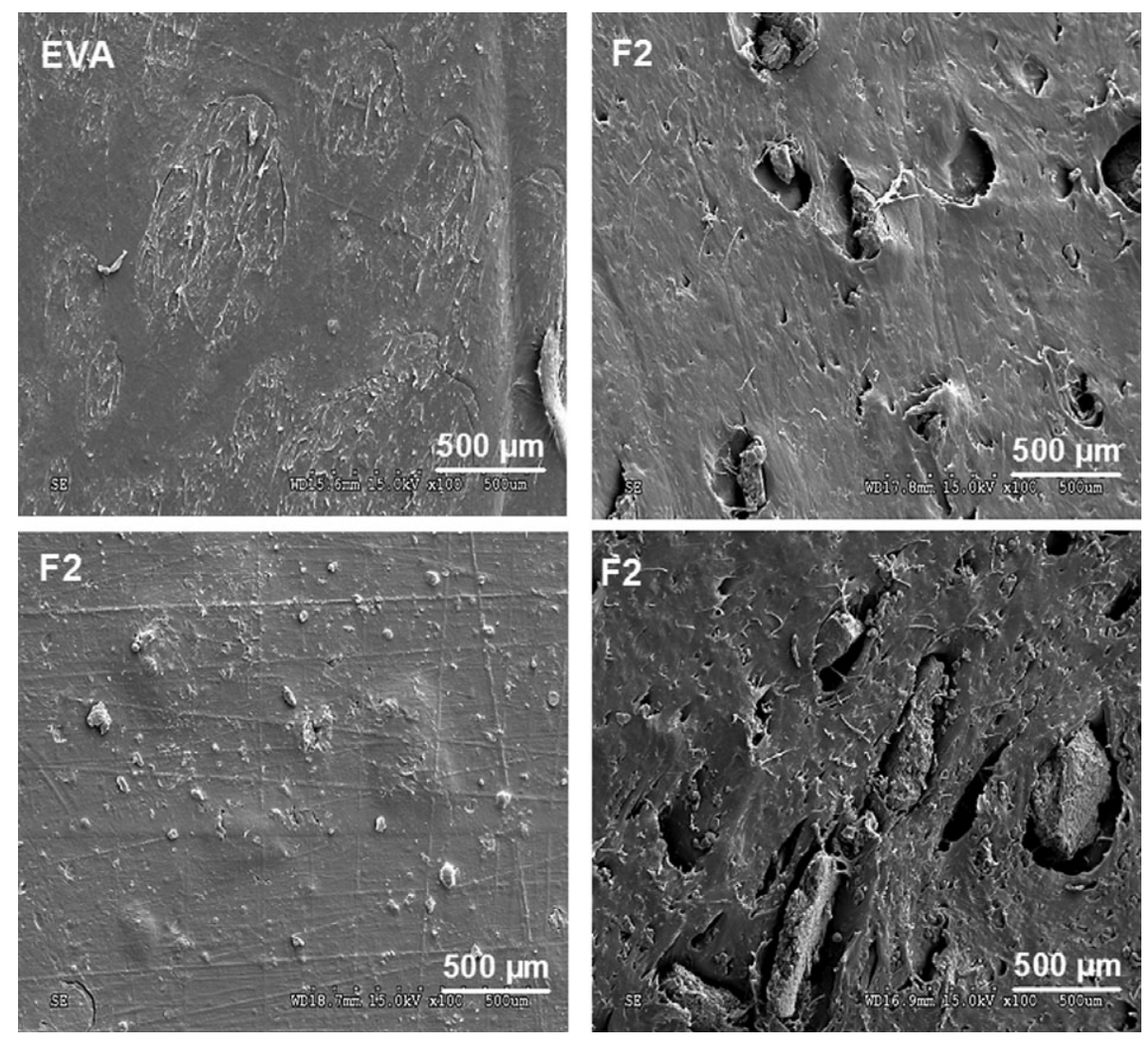

FIG. 4. SEM micrographs of pure EVA (F0) and EVA/starch composites.

fractured surface of EVA and EVA/starch composites. The starch particles can be clearly observed in F1 and F3 EVA/ starch composites. The adhesion of starch to EVA matrix is poor because of the presence of voids at the interphase between starch and EVA matrix. For F2 composite, some starch particles are removed from the EVA matrix leaving small cavities on the surface. The absence of compatibility between EVA and starch is more significant with increasing the amount of starch in the composite, and the size of the starch particles is larger. The above results confirm the poor

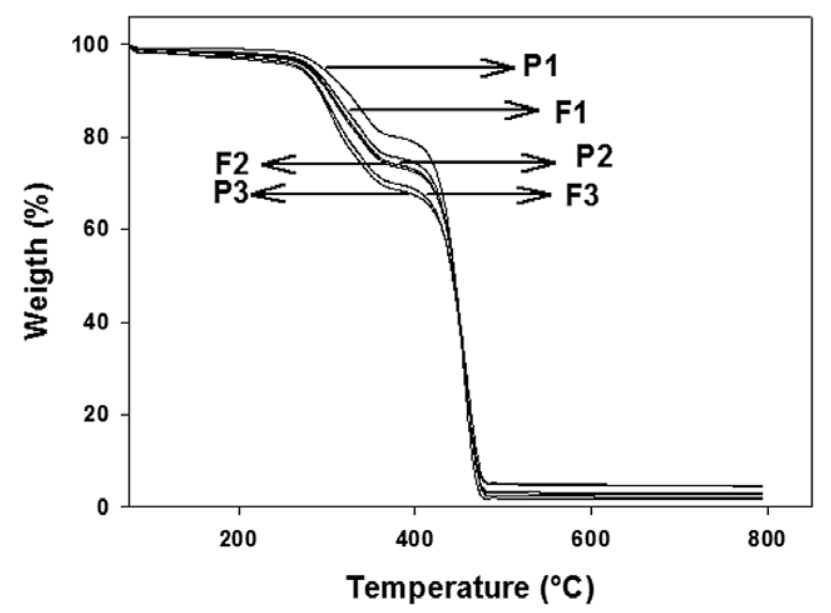

FIG. 5. Variation of the weight as a function of temperature for EVA/ starch composites without and with PE-g-MA. TGA experiments. interfacial adhesion between EVA and starch, which is consistent with the stress-strain data.

\section{EVA/Starch Composites Compatibilized With PE-g-MA}

The EVA/starch composites compatibilized with $5 \mathrm{wt} \%$ PE- $g$-MA are coded as P1, P2, and P3 (Table 1) and they contain 10, 20, and $30 \mathrm{wt} \%$ starch, respectively.

Table 2 shows some thermal characteristics obtained from the DSC thermograms of EVA/starch composites compatibilized with PE-g-MA. In general, the melting enthalpies of the composites with and without PE- $g$-MA are almost the same, whereas the crystallization enthalpies are slightly smaller in the compatibilized EVA/starch composites. In fact, the degree of crystallinity of the compatibilized EVA/starch composites (16-20\%) is somewhat close to those of the composites without compatibilizer. Further, the degree of crystallinity is somewhat lower in P3 composite containing $30 \mathrm{wt} \%$ starch, while the highest one corresponds to the compatibilized P2 composite having $20 \mathrm{wt}$ $\%$ of starch which can be attributed to the inhibited crystallization of EVA due to PE- $g$-MA. Indeed, Sam et al. [51] have shown that in LDPE/soya composites, the addition of PE- $g$-MA reduced the interfacial tension between the starch and the matrix due to the interactions between PE- $g$-MA and starch during extrusion. On the other hand, the compatibilized composite containing $30 \mathrm{wt} \%$ starch shows a decrease in the degree of crystallinity (Table 2) due 

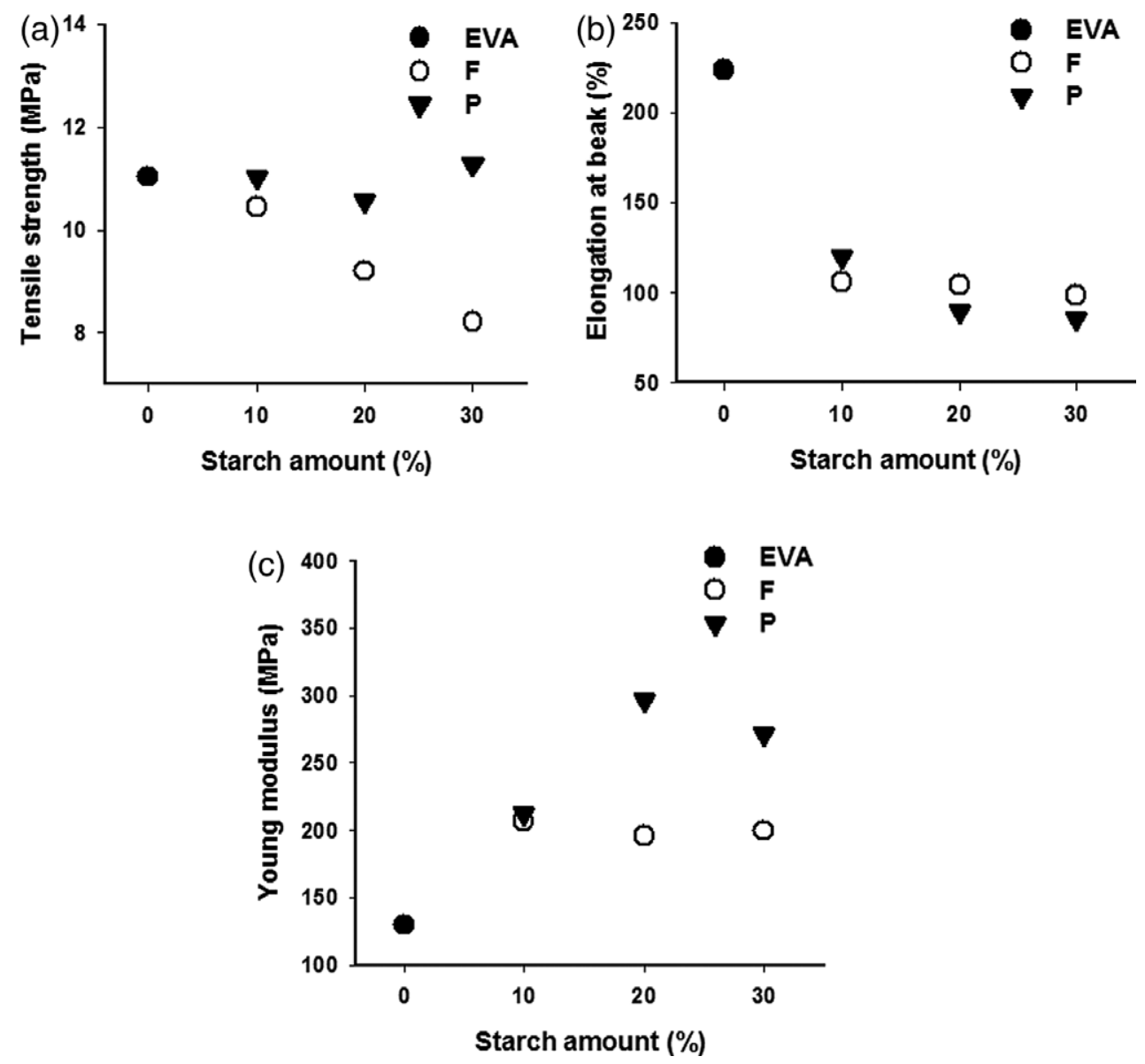

FIG. 6. Variation of the tensile strength (a), elongation at break (b), and Young modulus (c) for EVA/starch composites without and with PE-g-MA.

probably to the low amount of PE- $g$-MA. This is in agreement with the data reported by Liu et al. [52] which have demonstrated that the addition of $<10 \mathrm{wt} \%$ of PE- $g$-MA in LPDE/starch composites produced unsaturated interface between LDPE and starch, and subsequently, the interfacial adhesion is weak.

The TGA thermograms of EVA/starch composites without and with PE- $g$-MA are shown in Fig. 5. The thermal stability of EVA/10 wt\% starch is noticeably improved when PE- $g$-MA is added. However, Fig. 5 reveals that almost similar thermal stability is observed for the rest of the composites, irrespective of their PE- $g$-MA content. The improved thermal stability of the compatibilized EVA/10 wt\% starch composite is due probably to an enhancement of the interfacial adhesion between EVA and starch. This is in a concordance with the literature [45].

Figure 6 shows the variation of the mechanical properties of EVA/starch composites without and with PE- $g$-MA as a function of their starch content. The addition of PE-gMA produces an increase in both tensile strength and Young's modulus of EVA/starch composites with respect to neat EVA. On the other head, similar values of elongation at break are obtained for both uncompatibilized and PE- $g$-MA compatibilized composites. Moreover, Fig. 6 shows also a significant improvement of Young's modulus and the tensile strength for the composites with $20-30 \mathrm{wt} \%$ starch. According to Rohani et al. [27], the increased tensile strength in compatibilized LDPE/starch composites with PE- $g$-MA has been ascribed to the positive impact of the compatibilizer on the stress transfer which hinders the interfacial debonding. This leads to enhanced interfacial adhesion between the matrix and the starch, and subsequently an increase in the mechanical properties. Similar results are reported in literature [53-55].

The morphology of EVA/starch composites without and with PE-g-MA is shown in Fig. 7. The number and size of voids in the fractured surface of the composites are reduced in the presence of PE- $g$-MA. Adhesion of starch particles to EVA matrix is better for the composite containing $20 \mathrm{wt} \%$ starch (P2), this means that the interfacial tension is decreased. Bikiaris and Panayiotou [24] have suggested that the formation of a macromolecule produced by reaction between PE- $g$-MA and starch acted as an emulsifier reducing the interfacial tension between the polymer and the starch. On the other hand, the compatibilized EVA/30 wt\% starch composite shows smaller starch particles into the voids and some adhesion is also noticed. Therefore, the addition of PE-g-MA increases partially the interfacial adhesion of the starch particles in the EVA matrix. 

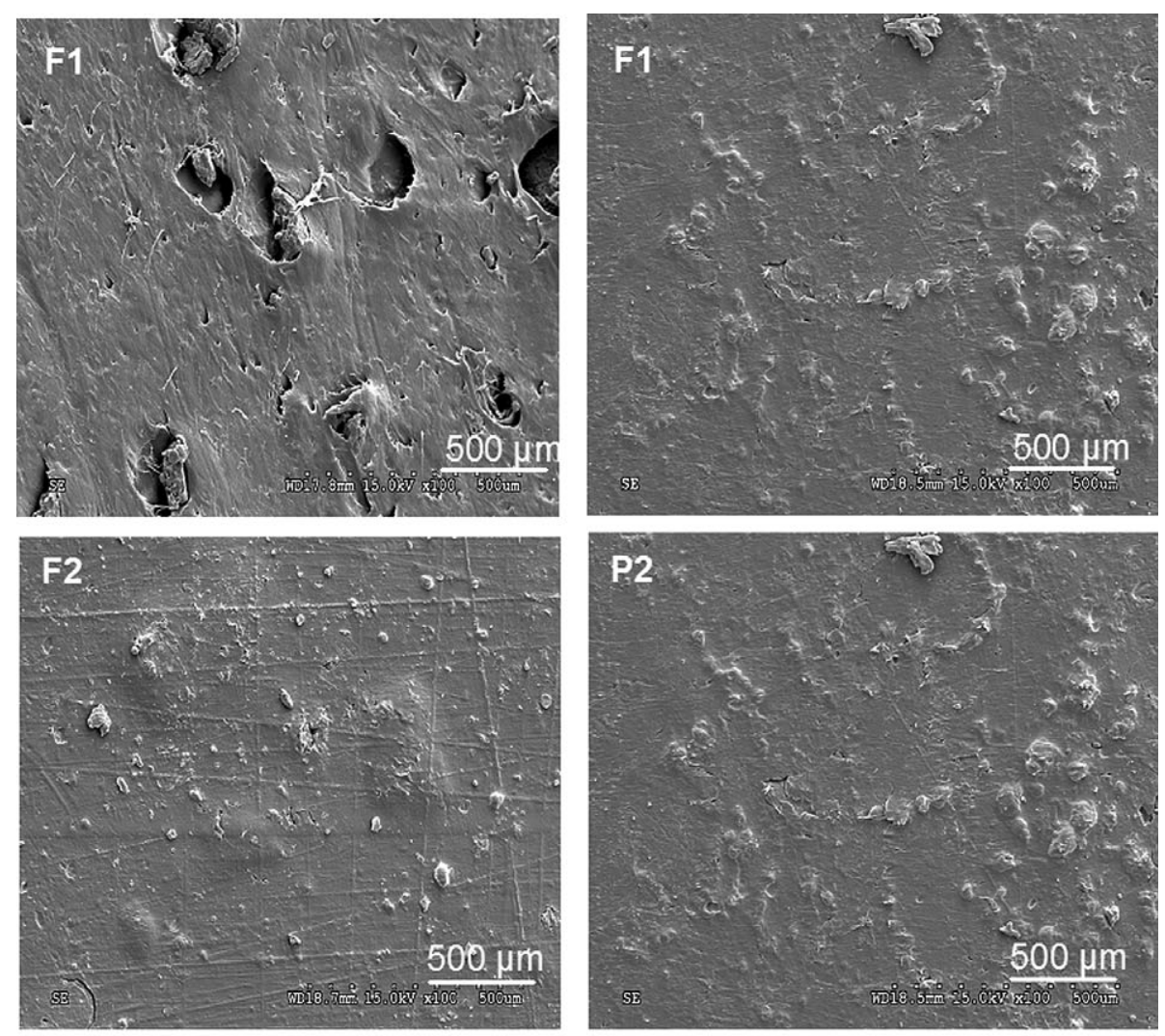

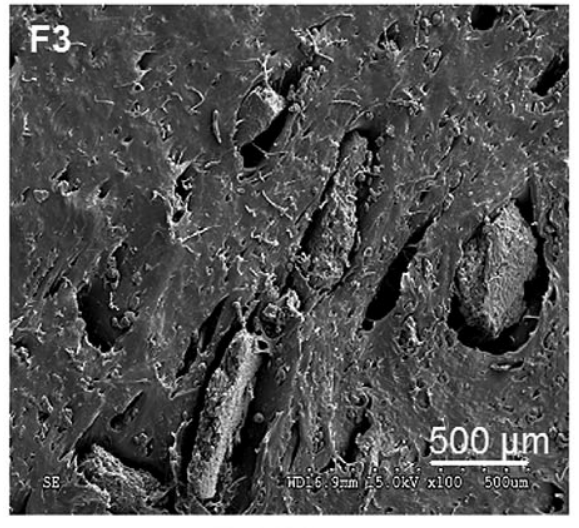

EVA/Starch

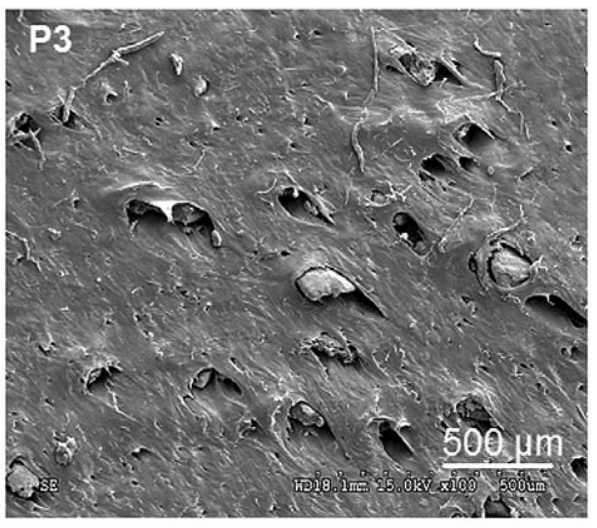

EVA/Starch/PE-g-MA

FIG. 7. SEM micrographs of EVA/starch composites without and with PE-g-MA.

\section{EVA/Starch Composites Compatibilized With MA and BPO Through Reactive Extrusion}

The EVA/starch composites containing 0.09 wt $\%$ MA and 0.009 wt\% BPO are coded as L1, L2, and L3 in Table 1 and they contain 10, 20, and 30 wt $\%$ starch, respectively.

Table 2 shows some thermal characteristics obtained from the DSC thermograms of MA + BPO compatibilized EVA/starch composites. In general, the melting enthalpies of the composites with and without $\mathrm{MA}+\mathrm{BPO}$ are quite similar $(35-43 \mathrm{~J} / \mathrm{kg})$, but the crystallization enthalpies are slightly lower in MA + BPO compatibilized EVA/starch composites. Indeed, the degree of crystallinity of MA +
BPO compatibilized EVA/starch composites (17-19\%) is almost similar to that of the uncompatibilized composites and even lower than for neat EVA. The results are in a good agreement with those reported by Aburto et al. [56] who have found a decrease in the crystallinity of polycaprolactone/starch blends prepared by reactive extrusion. The lower crystallinity in the compatibilized composites was explained by the difficulty of the polymer chains to arrange themselves when they contained high amount of starch. This is also due to the hydrophilic character of the starch, causing a steric effect leading to low adhesion to the hydrophobic polycaprolactone.

The TGA thermograms of EVA/starch composites without and with MA + BPO are shown in Fig. 8. The thermal 


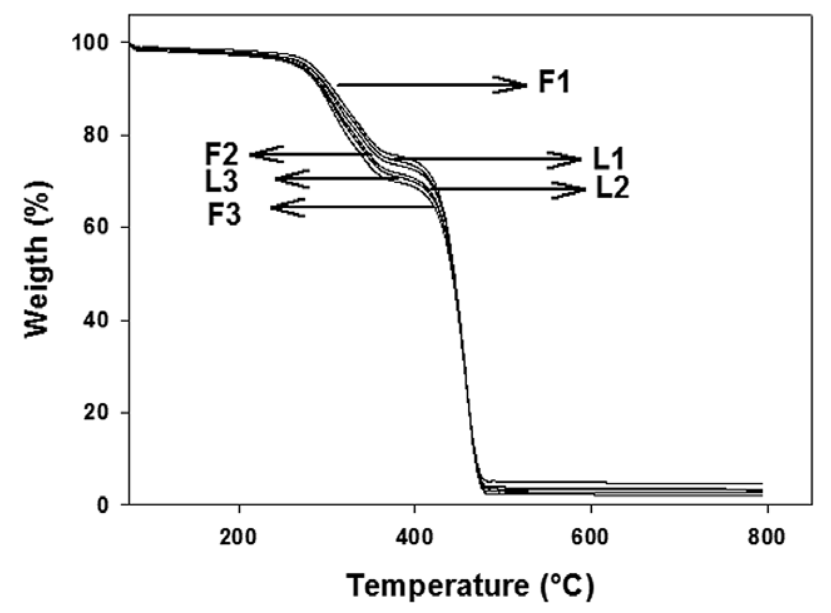

FIG. 8. Variation of the weight as a function of temperature for EVA/ starch composites without and with MA + PBO.TGA experiments.

stability of EVA/starch (30 wt\%) composite is significantly improved in the presence of MA and BPO; however, the extent of the increase is almost similar to that of uncompatibilized composites. Probably, the increase of the starch content enhances the wettability of the starch to the EVA matrix in the presence of MA + BPO. Indeed, Wang et al. [28] have shown the improved wettability between starch and PLA by adding $0.5 \mathrm{wt} \% \mathrm{MDI}$, particularly at a higher starch content. When the amount of starch increases, the mixing time of the composites to reach the set temperature is higher, and a few amount of PLA is degraded.

Figure 9 shows the variation of the mechanical properties of EVA/starch composites without and with MA + BPO as a function of their starch content. The addition of $\mathrm{MA}+\mathrm{BPO}$ increases the tensile strength and Young's modulus of EVA/starch composites. However, a decrease in the elongation at break is observed, in agreement with the literature [15,57]. Further, similar values of elongation at break are obtained for both uncompatibilized and MA + BPO compatibilized composites. It is also observed that higher Young's modulus and tensile strength values are obtained in the composites with 20 and $30 \mathrm{wt} \%$ starch. The improved mechanical properties of the compatibilized composites are ascribed to the improvement of the interfacial adhesion between starch and EVA [15,58]. The addition of $\mathrm{MA}+\mathrm{BPO}$ compatibilizer in EVA/starch composites increases the modulus due probably to a reaction between the maleated EVA and the starch. The slippage at the matrix-filler interfaceis reduced causing improved interfacial adhesion [15].

The morphological characterization of the fracture surfaces of the EVA/starch composites compatibilized by insitu grafting with MA and BPO is investigated by SEM. The SEM micrographs of the composites are shown in
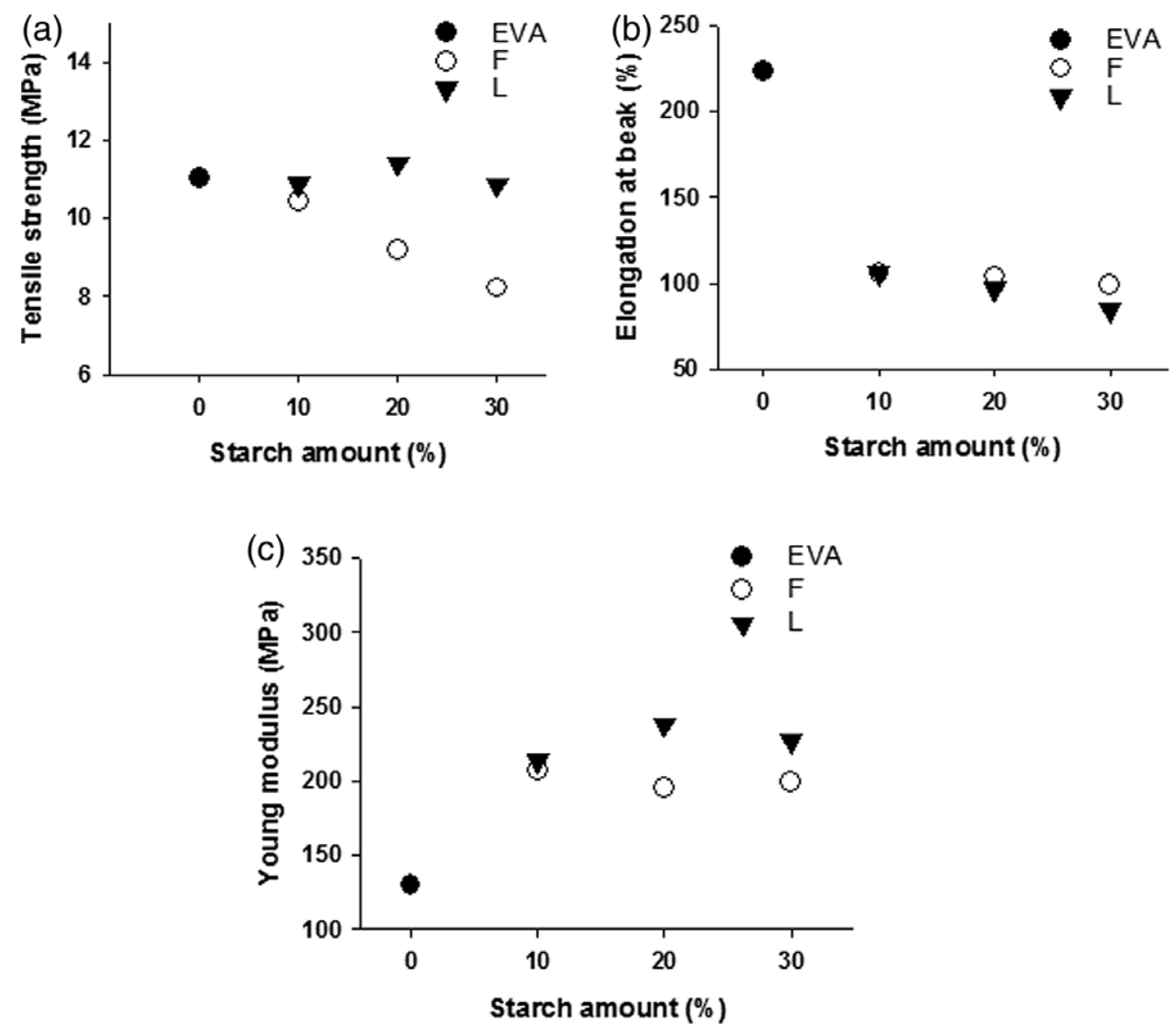

FIG. 9. Variation of the tensile strength (a), elongation at break (b), and Young modulus (c) for EVA/starch composites without and with MA + BPO. 

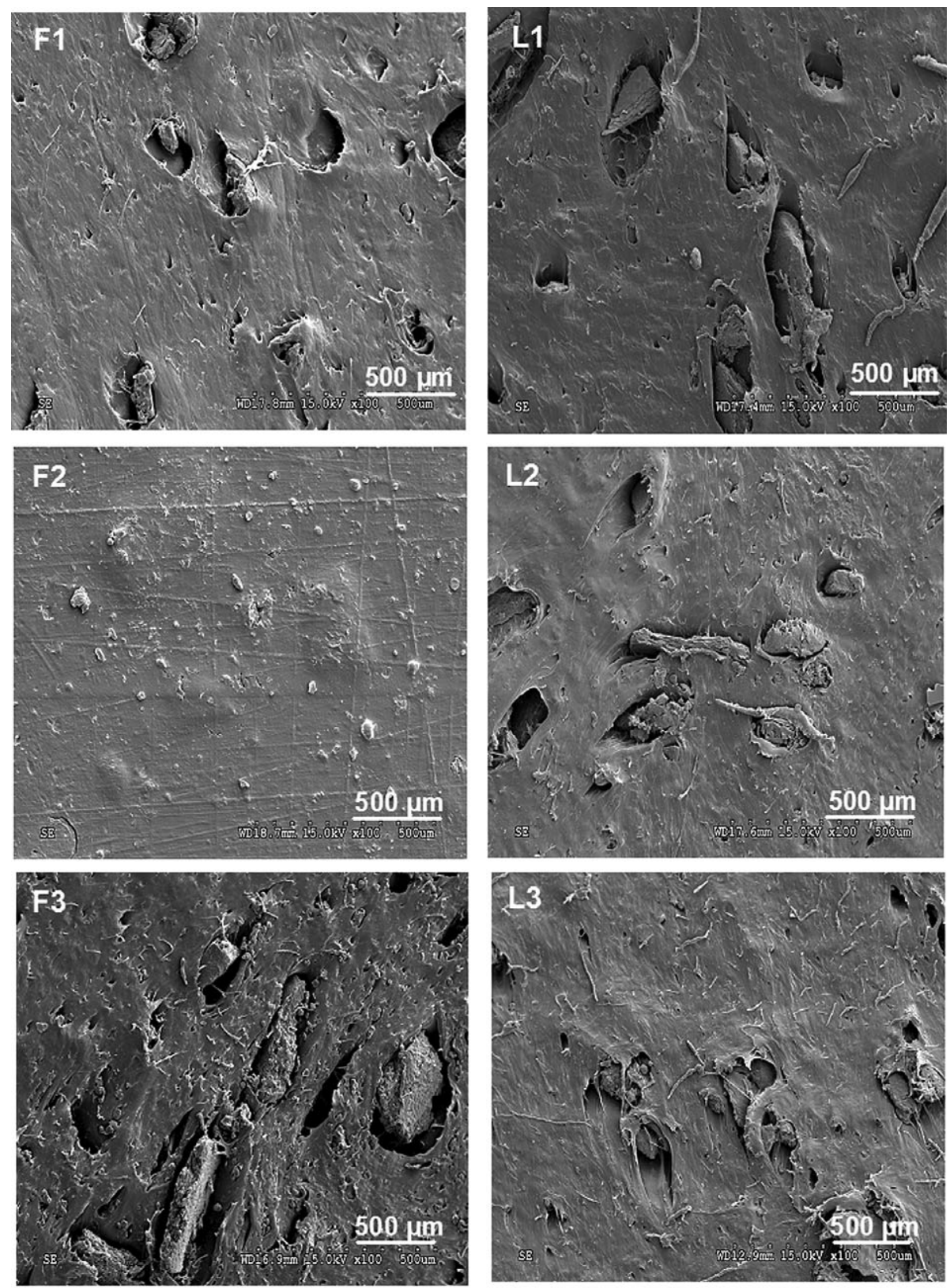

EVA/Starch

EVA/Starch/MA+PBO

FIG. 10. SEM micrographs of EVA/starch composites without and with MA + BPO.

Fig. 10. It is observed that in the absence of MA and BPO in the composite, there are two separated phases, one corresponding to the EVA matrix and the other to the starch grains. Due to fracture, some starch particles are removed from the EVA matrix leaving cavities on the surface of the composite, due likely to the weak interfacial adhesion between the hydrophilic starch and the hydrophobic EVA. The addition of MA and PBO yields to better interactions between the starch and the EVA as shown in Fig. 10. Indeed, the number of cavities on the fracture surfaces of the MA + BPO compatibilized composites is reduced. The starch phase detachment along the EVA-starch interface [46] indicates that the addition of MA + BPO improves the compatibility of EVA/starch composites. Further, the adhesion of the starch particles to EVA matrix is better in the composite containing $20 \mathrm{wt} \%$ (L2). In fact, Bikiaris and Panayiotou [24] reported finer and more uniform dispersion of starch in PE matrix in compatibilized blends with PE- $g$-MA copolymer.

\section{Comparison Between the Two Compatibilization Approaches in EVA/Starch Composites}

The comparison of the effects of adding different compatibilizers in EVA/starch composites has been carried out by selecting the ones containing $20 \mathrm{wt} \%$ starch. According to Table 2 , the crystallinity of the composite is not significantly affected by adding compatibilizer since $\Delta H_{\mathrm{m}}$ 


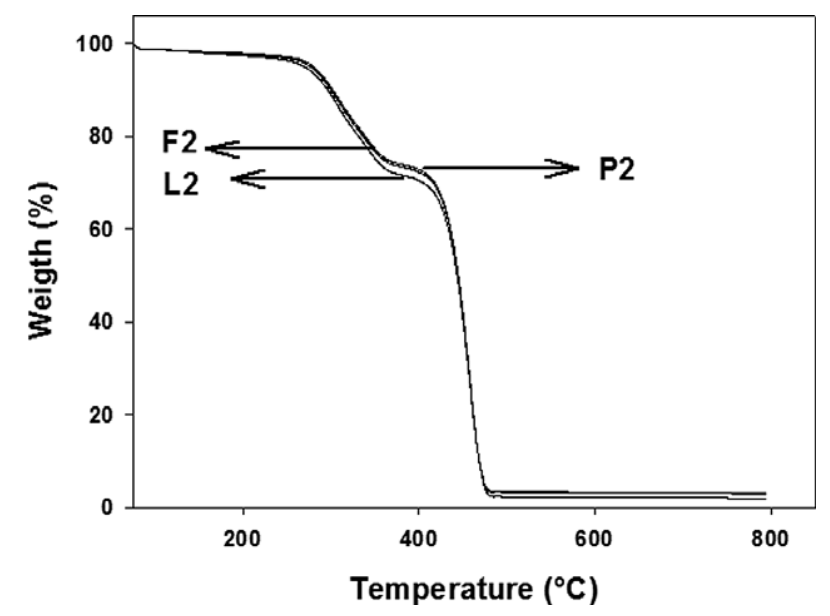

FIG. 11. Variation of the weight as a function of temperature for EVA/20\%starch composites without and with compatibilizers. TGA experiments.

remains constant. This can be ascribed to the presence of humidity in the starch which can react with the anhydride reactive groups of MA producing urea structure. This may be responsible for the lack of increase of the crystallinity of EVA/starch composites. Alternatively, the lack of influence of the compatibilizers on the crystallinity of EVA/starch composites can be ascribed to the low starch content which increases the probability of homopolymerization of MA leading to low molar mass plasticizer [58]. On the other hand, Fig. 11 shows that the thermal stability of PE- $g$-MA compatibilized EVA/starch (20 wt\%) composite is slightly higher than for the non-compatibilized composite. However, the thermal stability of MA + BPO compatibilized composite is slightly lower probably due to poor wettability between the starch and the EVA when low starch amounts are added [28].

The addition of compatibilizers increases the tensile strength and Young's modulus of EVA/starch (20 wt\%) composites (Fig. 12), being much higher when PE- $g$-MA is used. However, the addition of both compatibilizers decreases the elongation at break of the composites, in agreement with the literature [11,57]. The increase of the mechanical properties observed for the composite with 20 wt\% starch compatibilized with PE-g-MA may be ascribed to co-crystallization between PE- $g$-MA and EVA matrix. This results in an improvement in the interfacial adhesion and stiffness of the composites [31].

SEM micrographs of the fracture surfaces of uncompatibilized and compatibilized EVA/starch (20 wt\%)composites are shown in Fig. 13. It is observed that the starch grains are impregnated with the EVA matrix when PE- $g$-MA is incorporated. Thus, the compatibilization by PE- $g$-MA is more efficient in EVA/starch composites than by MA + BPO further strengthens the adhesion between the starch and the EVA. This can be attributed to the strong chemical interactions
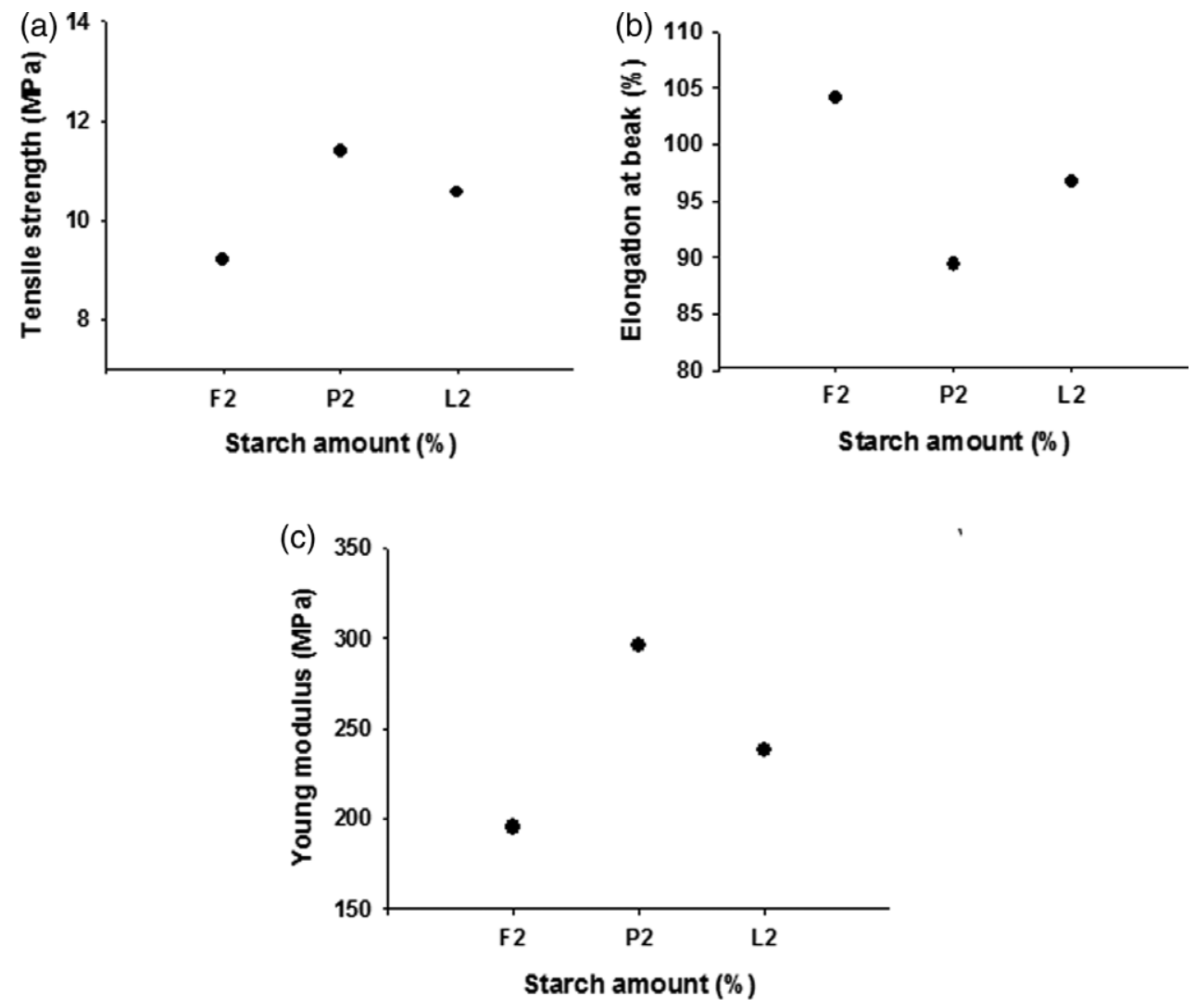

FIG. 12. Variation of the tensile strength (a), elongation at break (b), and Young modulus (c) of EVA/20 wt\% starch composites without and with compatibilizers. 

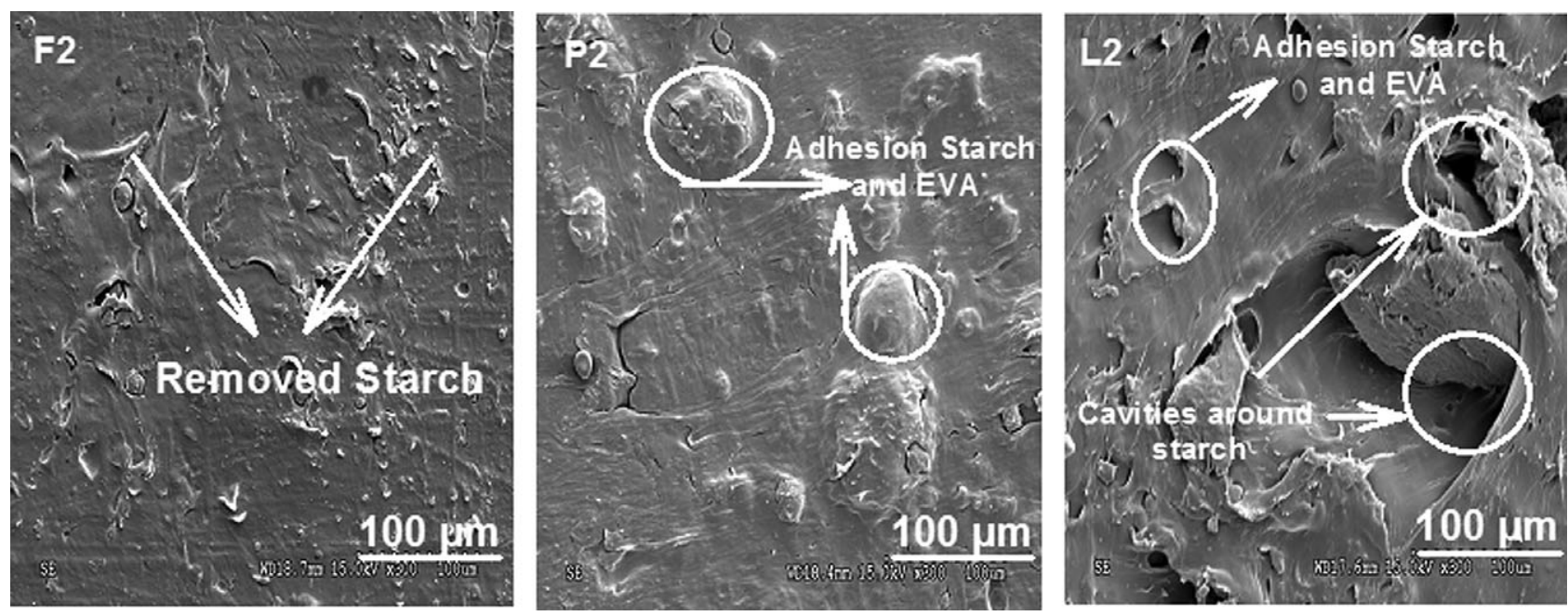

FIG. 13. SEM micrographs of compatibilized and uncompatiblized EVA/20 wt $\%$ starch composites.

between the hydroxyl groups of the starch and the anhydride groups of PE-g-MA and also to the physical interactions between EVA and PE- $g$-MA occurring in the extrusion process. On the other hand, for the grafting in-situ with MA and PBO, the radical grafting reaction between EVA and MA with peroxide can occur $[59,60]$ and an esterification reaction is expected between the grafted MA and the hydroxyl groups of the starch by reactive extrusion [20].

\section{CONCLUSIONS}

EVA/starch composites with two different compatibilization approaches have been prepared, the first one implies the addition of PE- $g$-MA in the composite materials, while the second one involves an in-situ grafting of MA on EVA in the presence of $\mathrm{PBO}$ through reactive extrusion. The morphology, thermal and mechanical properties of the composites allowed to select the most appropriate compatibilization method, which may be applied as per demands of industries such as the food packaging.

The addition of PE- $g$-MA to EVA/starch improved the thermal and mechanical properties of the composites depending on the starch amount. The degree of crystallinity of EVA/starch composites slightly increased with the starch content. On the other hand, the addition of PE- $g$-MA decreased the crystallinity, particularly above the starch content of $20 \mathrm{wt} \%$. The thermal stability of the composites increased in the presence of the compatibilizer. Furthermore, an increase in the tensile strength and Young's modulus was observed, more pronounced when PE- $g$-MA compatibilizer was added. The elongation at break decreased with increasing the starch content. Indeed, the composite with $30 \mathrm{wt} \%$ starch and compatibilized with PE$g$-MA had exhibits a smoother microstructure and the highest tensile strength value compared with the rest of the composites ( 11 MPa), SEM micrographs showed that the addition of $20 \mathrm{wt} \%$ starch imparted the highest adhesion, and the use of the compatibilizers also contributed to increase the interfacial interactions between the starch and the EVA.

In this study, the appropriate compatibilization method in EVA/starch composite was selected according to the starch content. The addition of PE-g-MA compatibilizer improved the thermal proprieties at the starch content of $20 \mathrm{wt} \%$, but the increase of the starch content in the composite decreased the thermal properties. Also, the addition of $20 \mathrm{wt} \%$ starch imparted the highest adhesion and, moreover, the mechanical proprieties were improved for the composites with 20-30 wt\% starch. As for grafting in-situ with MA and PBO, the thermal stability and mechanical proprieties were improved by adding higher amounts of starch, and the thermal stability of EVA/starch (30 wt\%) was significantly improved and had a highest tensile strength as compared with the composites with 10 and $20 \mathrm{wt} \%$ starch $(<11 \mathrm{MPa})$.

The plasticization is an important factor that influences the properties of composites prepared with starch. Furthermore, the addition of fillers should play an important role in the compatibilization and mechanical properties of EVA/starch composites. Therefore, in future studies, the addition of plasticizer and/or filler to the EVA/starch system compatibilized by PE-g-MA and $\mathrm{MA}+\mathrm{PBO}$ reactive extrusion and their biodegradation will be considered.

\section{REFERENCES}

1. E.J. Choi, C.H. Kim, and J.K. Park, J. Polym. Sci., 37, 2430 (1999).

2. R. Shi, A.C. Zhu, D.F. Chen, X.J. Jiang, X.C. Xu, L. Q. Zhang, and W. Tian, J. Appl. Polym. Sci., 115, 346 (2010).

3. N. Reddy and Y.Q. Yang, Biotechnol. Bioeng., 103, 1016 (2009). 
4. M.E. El-Naggar, M.H. El-Rafie, M.A. El-sheikh, S. El-Feky, Gina, and A. Hebeish, Int. J. Biol. Macromol., 81, 718 (2015).

5. G.S. El-Feky, M.H. El-Rafie, M.A. El-Sheikh, M.E. ElNaggar, and A. Hebeish, J. Nanomed. Nanotechnol., 6, 254 (2015).

6. G.J.L. Griffin, Br. Pattern., 586, 344 (1973).

7. S. Kiatkamjornwong, P. Thakeow, and M. Sonsuk, Polym. Degrad. Stab., 73, 375 (2001).

8. O. Lopez, M.A. Garcia, M.A. Villar, A. Gentili, M. S. Rodriguez, and L. Albertengo, Food Sci. Technol., 57, 106 (2014).

9. S. Sahi, H. Djidjelli, and A. Boukerrou, J. Polym. Eng., 36, 245 (2016).

10. A. Hebeish, T.I. Shaheen, and M.E. El-Naggar, Int. J. Biol. Macromol., 87, 70 (2016).

11. A. Hebeish, M.E. El-Naggar, and M.A. El-sheikh, J. Onorg. Organomet. Polym., 24, 515 (2014).

12. M.H. El-Rafie, M.E. El-Naggar, M.A. Ramadan, M.M. G. Fouda, S.S. Al-Deyab, and A. Hebeish, Carbohydr. Polym., 86, 630 (2011).

13. N.L. Garcia, L. Ribba, A. Dufresne, M. Aranguren, and S. Goyanes, Carbohydr. Polym., 84, 203 (2011).

14. F.J. Rodriguez-Gonzalez, B.A. Ramsay, and B.D. Favis, Polymer, 44, 1526 (2003).

15. R. Chandra and R. Rustgi, Polym. Degrad. Stab, 56, 185 (1997).

16. A.L.D. Roz, A.M. Ferreira, F.M. Yamaji, and A.J. F. Carvalho, Carbohydr. Polym., 90, 40 (2012).

17. R.R.N. Sailaja, Polym.Int., 54, 296 (2005).

18. R.R.N. Sailaja and M. Chanda, J. Appl. Polym. Sci., 86, 3134 (2002).

19. M.A. Huneault and H. Li, Polymer, 48, 270 (2007).

20. J.F. Zhang and X. Sun, Biomacromolecules, 5, 1446 (2004).

21. J.F. Zhang and X. Sun, Macromol. Biosci., 4, 1053 (2004).

22. N. Wang, J. Yu, and X. Ma, Polym. Int., 56, 1440 (2007).

23. M. Piming, Macromol. Res., 20, 1054 (2012).

24. D. Bikiaris and C. Panayiotou, J. Appl. Polym. Sci., 70, 1503 (1998).

25. A.G. Pedroso and D.S. Rosa, Polym. Adv. Sci., 16, 317 (2005).

26. A.W.M. Kahar, H. Ismail, and N. Othman, J. Vinyl. Add. Technol., 18, 70 (2012).

27. A.M. Rohani, H. Ismail, and M.T. Razaina, J. Iran. Polym., 19, 510 (2010).

28. H. Wang, X. Sun, and P.J. Seib, J.Appl. Polym. Sci., 84, 1257 (2002).

29. W. Shujun, Y. Jiugao, and Y. Jinglin, Polym. Int., 54, 279 (2005).

30. L. Chen, X. Qiu, Z. Xie, Z. Hong, J. Sun, X. Chen, and X. Jing, Carbohydr. Polym., 65, 75 (2006).

31. E. Schwach, J.L. Six, and L. Averous, J. Polym. Env., 16, 286 (2008).

32. W. Shujun, Y. Jiugao, and Y. Jinglin, Polym. Degrad. Stab., 87, 395 (2005).
33. J. Ratnasingam, T.C. Tek, and S.R. Farrokhpayam, J. Appl. Polym Sci., 8, 1596 (2008).

34. A. Sonia and K.P. Dasan, J. Food. Eng., 118, 89 (2013).

35. D. Wei-hua, G. Zhang, Z. Zhu-Di, and Y. Peng, Polym. Int., 53, 454 (2004).

36. Y. Bai, J. Qian, A. Quanfu, Z. Zhu, and P. Zhang, J. Membr. Sci., 305, 159 (2007).

37. M. Gonzalez-Alriols, A. Tejado, M. Blanco, I. Mondragon, and J. Labidi, J. Chem. Eng., 148, 114 (2009).

38. H.A. Khonakdar, U. Wagenknecht, S.H. Jafari, R. Hässler, and H. Eslami, Adv. Polym. Technol., 23, 307 (2004).

39. H.J. Kim, J.J. Lee, J.C. Kim, and Y.C. Kim, Ind. Eng. Chem., 16, 406 (2010).

40. M.P. Anderson, R. Ruthe, and L.O. Rodrigo, Carbohydr. Polym., 136, 210 (2016).

41. R.S. Jagadish and R. Raj, Food. Hydrocoll., 25, 1572 (2011).

42. M. Sabetzadeh, R. Magheri, and M. Masoomi, Carbohydr. Polym., 119, 126 (2015).

43. C. Fang-Chyou, S.M. Lai, and K.T. Ti, Polym. Test., 28, 243 (2009).

44. J.A. Jofre-Reche and J.M. Martín-Martínez, Int. J. Adhes. Adhes., 43, 42 (2013).

45. J.F. Mano, D. Kpniarova, and R.L. Reis, J. Mater. Sci., 14, 135 (2003).

46. D.G. Dikobe and A.S. Luyt, J. Appl. Polym. Sci., 103, 3654 (2007).

47. N. Chibani, H. Djidjelli, A. Dufresne, A. Boukerrou, and S. Nejma, Vinyl. Add. Technol., 22, 231 (2014).

48. M. Beztout, A. Boukerrou, H. Djidjelli, C. Barres, and F. Fenouillot, Cellulose Chem. Technol., 49, 517 (2015).

49. M. Mondragon, K. Arroyo, and J. Romero-Garcia, Carbohyd. Polym., 74, 20 (2008).

50. M. Ramakrishna, K. Vivek, and S.N. Yuvraj, Reinf. Plast. Comp., 28, 1169 (2009).

51. S.T. Sam, H. Ismail, and Z. Ahmad, Vinyl Add. Technol., 15, 259 (2009).

52. W. Liu, Y.J. Wang, and Z. Sun, J. Appl. Polym. Sci., 88, 2904 (2003).

53. A. Gupta, V. Kumar, and M. Sharma, J. Polym. Environ., 18, 484 (2010).

54. A. Taghizadeh, P. Sarazin, and B.D. Favis, Mater. Sci., 48, 1799 (2013).

55. A. Taguet, P. Sarazin, and B. Favis, Polymer., 50, 5733 (2009).

56. J. Aburto, S. Thiebaud, I. Alric, D. Bikiaris, J. Prinos, and C. Panayiotou, Carbohydr. Polym., 34, 101 (1997).

57. P. Matzinos, D. Bikiaris, S. Kokkou, and C. Panayiotou, J. Appl. Polym. Sci., 79, 2548 (2001).

58. V.H. Orozco, W. Brostow, W. Chonkaew, and B.L. López, Macromol. Symp., 277, 69 (2009).

59. J. Yin, J. Zhang, and Y. Yao, J.Appl. Polym. Sci., 841, 102 (2006).

60. J. Kim, B.S. Shin, J.L. Hong, W.J. Cho, and C.S. Ha, Polymer., 42, 4073 (2001). 